\title{
Die Raumstation
}

\author{
Erhard Taverna
}

Sie hat etwas Utopisches, die riesige Halle mit dem milchig hellen Kunsthimmel. Modernste Technik für eine nachgebaute Wildnis, eine biotopische Intensivstation, wie unsere industrielle Zivilisation. Die 27 Meter hohe Metallkonstruktion überwölbt eine Fläche von zwei Fussballfeldern. Aus den tragenden Pfeilern strömen täglich vier Mal Regen und Nebel in die Wipfel der frisch gesetzten Urwaldbäume, die schnell dem lichtdurchlässigen Foliendach entgegenwachsen. Noch werden Pflanzen beschriftet, ein rötliches Gemisch von Mineralien und Lava wird durch ein Rohr geblasen, Baumaschinen transportieren Steine und abgepackte Schösslinge, in den Vorhallen wird gemalt, gesägt und gehämmert.

\section{Der Bau}

Im Februar 2001 wurde mit dem Baubeginn umgesetzt, was 1991 als langfristige Projektidee heranreifte. Im grössten Gebäude der Stadt Zürich wird man bald auf Lehrpfaden im feuchten Regenwald Lemuren beobachten, auf schwankenden Seilbrücken im Sumpf bunte Frösche quaken und bei Kaffee und Kuchen durch das Panoramafenster Zwerghaubenfischer beobachten können. Seit Carl Hagenbeck die naturnahe gestaltete,

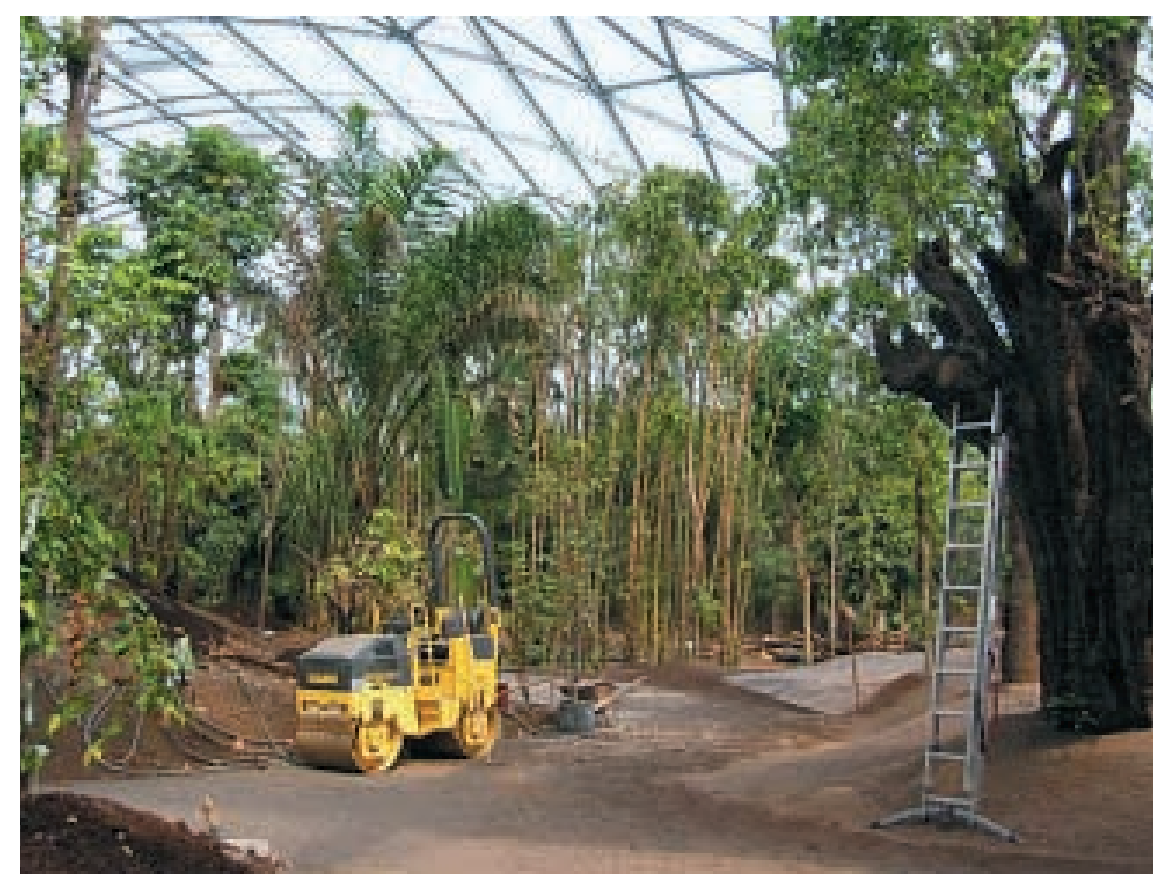

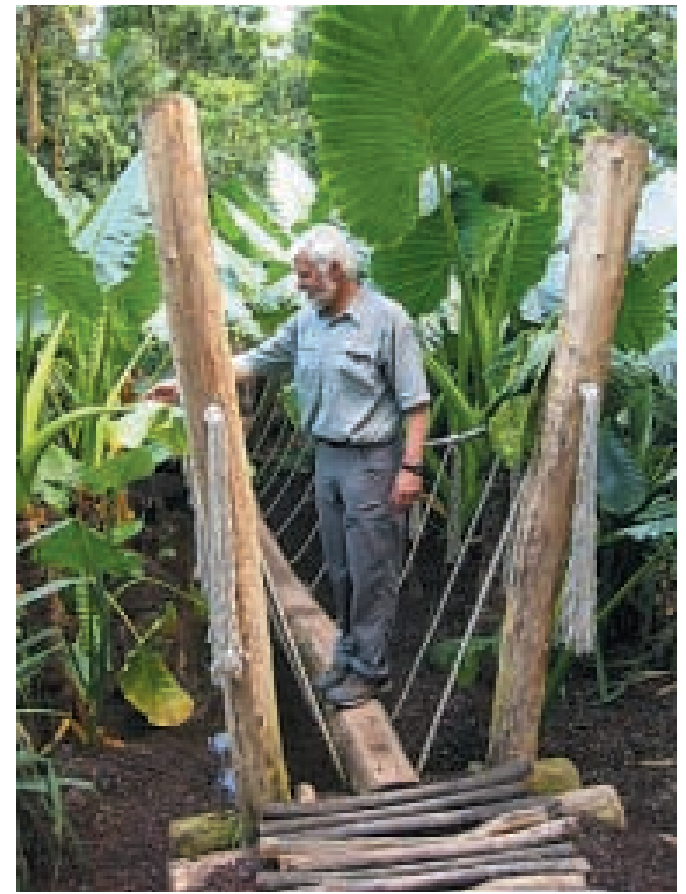

gitterlose Freisichtanlage erfunden hat, gilt was der berühmte Erfinder Edison bei einem Besuch gesagt haben soll: «The animals are not in the cage, they are on stage.» Kein Hauch von Menagerie oder Berner Bärengraben. Hier können nur noch Fundis von vermeintlicher Gefangenschaft reden. Eine exklusive Gesellschaft wird hier Revier, Nahrung und Sicherheit bekommen. Kaum Konkurrenz, keine Jäger, dafür lauter besorgte Spezialisten, Zoologen, Botaniker, Tierärzte und Ingenieure. Mehr als 10002 bis $13 \mathrm{~m}$ hohe Bäume, 13000 Pflanzen und 4000 Orchideen wurzeln im neuen Untergrund. Sie haben lange Reisen hinter sich, von Thailand und Kalifornien im Schiff nach Holland und Belgien, um nach genormter Aufzucht, befreit von unerwünschten blinden Passagieren, tonnenschwer auf Tieflastern in die Schweiz zu fahren. Sie gedeihen gut im vorläufig letzten Treibhaus, wachsen zum Blätterdach über Teichen und Wasserläufen und kriechen über die gemalten Kunstfelsen. Schleusen bewahren die geschlossene Gesellschaft vor einheimischen Nagern und Parasiten. «Do you know which is the most dangerous animal in the zoo?» war im Zoo von Pondicherry zu lesen. Ein Pfeil zeigte auf einen Vorhang, hinter dem sich ein Spiegel verbarg. Yann Martels Bestseller «The Life of Pi» erzählt nicht nur von einer spannen- 


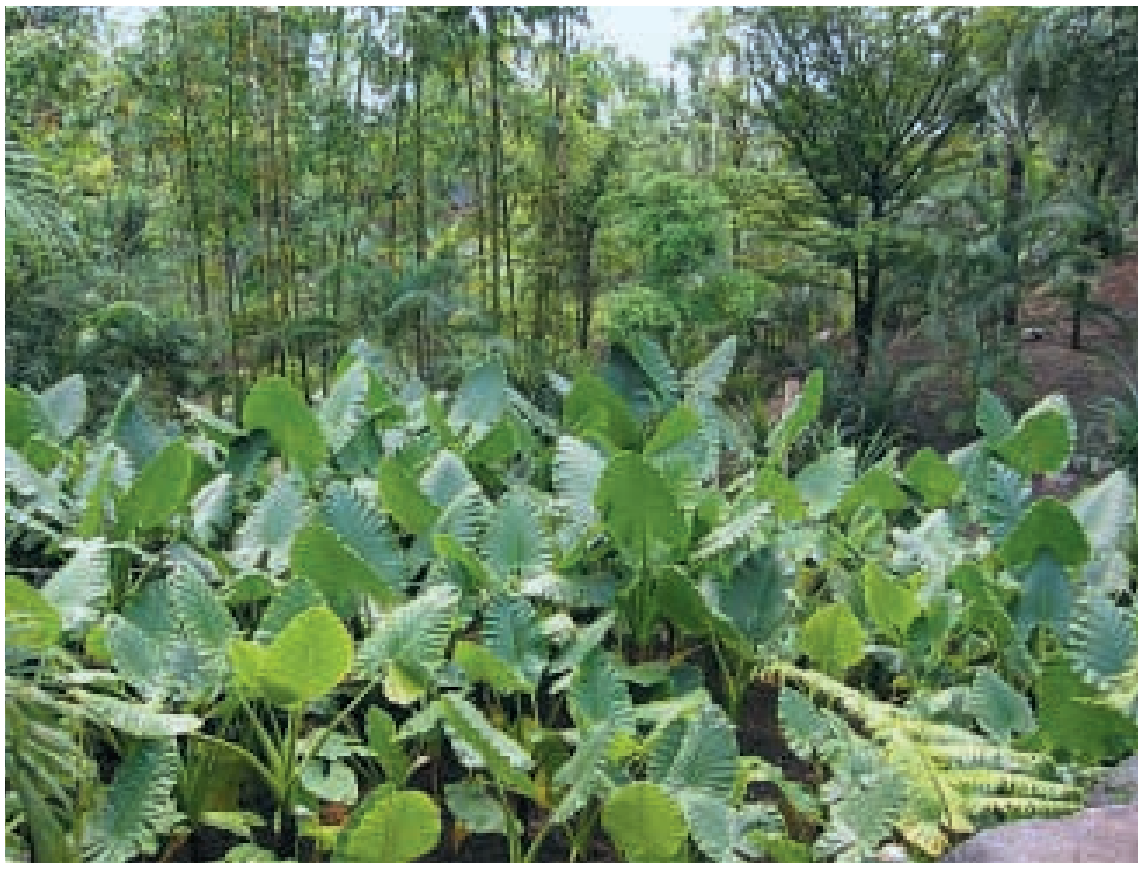

den Irrfahrt über den Pazifik im Rettungsboot mit Tiger, wir erfahren auch eine Menge über richtige Tierhaltung und perverse oder aggressive Zoobesucher. Bald werden diese, zur Freude der Verwaltung, zu Tausenden die Eingänge passieren, die einzige Gefahr für die Freiheit der Mausmaki, Fingertiere, roten Vari, Chamäleons, Frösche, Vögel und Tenreks, den wahren Astronauten.

\section{Die Idee}

Zoologische Gärten wurden schon im alten China vor Jahrtausenden angelegt. Heute soll es mehr als 10000 Tiergärten geben, die jährlich von mindestens 600 Millionen Menschen, mehr als jede andere öffentliche Einrichtung, besucht werden. Das Konzept ist in einem dauernden Wandel, soll Freizeitgestaltung, Forschung, Naturschutz, Pädagogik und wirtschaftliche Betriebsführung unter einen Hut bringen. Seit Jahren werden Projekte mit den Herkunftsländern verwirklicht, wobei der Elefantenstreit in Basel schon die internationalen Interessenkonflikte zwischen dem ökologisch fragwürdigen Unterhaltungsanspruch städtischer Besucher und den Bedürfnissen tropischer Länder offenlegte. Der Zürcher Zoo beschreitet auch ideell neue Wege in seiner Zusammenarbeit mit madagassischen Behörden, lokalen Naturschützern, der «Wildlife Conservation Society» und der Entwicklungshilfeorganisation CARE. Das neue Ökosystem wird als Naturschutzzentrum begriffen, das die Artenvielfalt und die schonende Nutzung des Maosala Nationalparks im Nordosten der Insel mit seinen Regenwäldern, Mangrovensümpfen und Korallenbänken sichern soll. Der arme Süden liefert Pflanzen und Tiere im Austausch gegen ein Schutzprogramm aus dem reichen Norden. Die lokale Bevölkerung verzichtet auf Brandrodungen für den Anbau von Reis- und Vanillefeldern und züchtet dafür Pflanzen für Nahrungsmittel, Medikamente und zur Zierde, oder widmet sich dem sanften Tourismus.

Die neue Strategie will das Verständnis für die gefährdeten Regenwälder fördern. Der Zoo als naturkundliche Bildungsstätte verbindet das emotionale Erlebnis mit einem pädagogischen Auftrag. Das Gleichgewicht wäre dann erreicht, wenn in Madagaskar ein Gegenstück eröffnet würde, mit einem künstlich beregneten Tösswald, mit Luchs, Bär und Fischotter und guten Ratschlägen für die Rekultivierung des schweizerischen Mittellandes, nebst sanftem Entzug von unserer geliebten Autosucht. 